\title{
Research of Opportunistic Behavior in School-enterprise Cooperation
}

\author{
Xiao-Ying $L A I^{1,3, a}$, Zheng-Ming YUAN ${ }^{*}, 2, b$ \\ ${ }^{1}$ National Engineering Research Center of Phosphato Resources Development and Utilization, \\ Wuhan Institute of Technology, Wuhan430073, PR China \\ ${ }^{2}$ Wuhan Institute of Technology, Wuhan430073, PR China \\ ${ }^{3}$ Hohai University, Nanjing 210098, China \\ a4351842@qq.com, b1211140588@qq.com \\ ${ }^{*}$ Corresponding author
}

Key Words: School-enterprise cooperation, Opportunistic behavior.

\begin{abstract}
There are many problems in the school-enterprise cooperation, caused by its self-protection of universities or enterprises which based on its own interests in the cooperation. In this paper, the game theory is adopted as the basic theory for the author who tries to apply the modeling method to construct a simple model, taking the analysis of school-enterprise cooperation should adopt the way to achieve the optimal solution, offer the decision basis for cooperation.
\end{abstract}

\section{Introduction}

The cooperation between schools and enterprises is based on the interests of each other. The author thinks that the School-Enterprise Cooperation is divided into two categories: One kind is the school running model which is built on the Occupation Schools. For their development and the improvement of the education quality, the occupation schools always adopt the cooperation with enterprises, and the development direction of talent focus on practicability and effectiveness. The combination of learning and practice is a kind of win-win situation model. Another kind of cooperation is scientific research model. Because of the integration which based on the production, learning and research, cooperation between schools and enterprises increasingly turned to research and engineering technical cooperation model. Most enterprises do not have their own R\&D team, in order to adapt to the fierce market competition, they choose cooperation with schools and with the help of the schools to fill their research blank; At the same time, schools also have the aid of the capital which from enterprises to expand the construction and the promotion of achievements. The model by build, innovation, share resource and information is another kind of win-win situation model.

However, it's not subordinate relationship between schools and enterprises that the same achievements in scientific research always popularized to different enterprises by schools. For enterprises, the original power of cooperation with schools is the prospective of scientific research and with its help to base upon the market. The significance of cooperation between enterprises and schools is lost if the research results are widely spread. Moreover, development of any achievement needs a cycle. To adapt to the rhythm of the market, the enterprise often take cooperation with different schools in the same time that pose a threat to the schools who have worked for it. Facts prove that there have many opportunistic behaviors in the cooperation such as one will terminate the cooperation after it got another one's resources as much as possible. The existence of opportunism had prompted the parties involved in the cooperation to strengthen the protection of its own core interests, so that relationship loose.

\section{Modeling and analysis}

Easy to calculate, the author chooses two partners as an example to make preliminary study on the opportunistic behavior of the School - Enterprise Cooperation in this paper.

* Corresponding author: Main research interests are International Economics and Trade, 13871116555. 
1) A basic hypothesis of the model

By the behavior as shown in the process, the author divides both sides into two kinds, respectively reciprocators and opportunists. Assuming the proportionof opportunismis.

Assuming reciprocators and opportunists may both shows two kinds of behavior which are cooperation and betrayal.

Assuming reciprocators take cooperation strategy, and always take it, performance for mutual benefit and sharing results. If they take the betrayal strategy, they still performance for mutual benefit and sharing results in the beginning until they get the information or resources which they need. They will choose betrayal when noticed the other one existing opportunistic behavior.

If the opportunists choose cooperation strategy, theyare also reciprocators. Because of the betrayal strategy, they will hand to protect their own information or resources don't leak and one should obtain from the other onesin the process of cooperation and adopt termination cooperationafter they got from the other ones.

Assuming reciprocators take cooperation strategy to each other, in the opposite, the opportunists adopt betrayal strategy when the partnerstake cooperation strategy;Assuming reciprocators select betrayal as well as the partners adopt the same strategy.

2) Game pay-off matrix

Assuming that both sides cooperate, its successful probability $\mathrm{x}_{1}$, the success of the cooperation income is $\mathrm{R}_{1}$, its cost $\mathrm{C}_{1}$. After got information or resources from the other side, the successful probability for one side to adopt betrayal strategy and active alone is $\mathrm{v}_{1}$, cost is $\mathrm{C}_{2}$.

$\mathrm{v}_{1}<\mathrm{x}_{1}, \mathrm{C}_{2}>\mathrm{C}_{1}$

a) If both partners are reciprocators, successful probability for one who adopt betrayal

is $\mathrm{v}_{1}$, the cost is $\mathrm{C}_{2}$; Because of the resources are shared for reciprocators, so successful probability for one who adopt cooperation is also $\mathrm{v}_{1}$, cost is $\mathrm{C}_{3}$.

The incomeof reciprocators who take betrayal strategy is $\mathrm{R}_{2}$, The income of reciprocators who take cooperation strategy is $R_{3}$, and $R_{2}>R_{3}$. (Because one who adopts betrayal has the first mover advantages)

So, $\mathrm{R}_{2}>\mathrm{R}_{1}>\mathrm{R}_{3}, \mathrm{C}_{3}>\mathrm{C}_{2}>\mathrm{C}_{1}$

If both partners choose betrayal after got the other one's resources, the successful probability of each other is $\mathrm{v}_{1}$, cost is $\mathrm{C}_{2}$, income is $\mathrm{R}_{1}$.

Table 1 Game Matrix for both partners bereciprocators

\begin{tabular}{|c|c|c|}
\hline $\begin{array}{l}\text { reciprocator } \\
\text { reciprocator }\end{array}$ & Cooperation & Betrayal \\
\hline cooperation & $\left(\mathrm{x}_{1} \mathrm{R}_{1}-\mathrm{C}_{1}, \mathrm{x}_{1} \mathrm{R}_{1}-\mathrm{C}_{1}\right)$ & $\left(\mathrm{v}_{1} \mathrm{R}_{3}-\mathrm{C}_{3}, \mathrm{v}_{1} \mathrm{R}_{2}-\mathrm{C}_{2}\right)$ \\
\hline Betrayal & $\left(\mathrm{v}_{1} \mathrm{R}_{2}-\mathrm{C}_{2}, \mathrm{v}_{1} \mathrm{R}_{3}-\mathrm{C}_{3}\right)$ & $\left(\mathrm{v}_{1} \mathrm{R}_{1}-\mathrm{C}_{2}, \mathrm{v}_{1} \mathrm{R}_{1}-\mathrm{C}_{2}\right)$ \\
\hline
\end{tabular}

Because the reciprocators have cooperation preference, suppose that the expectation incomeby the game between tworeciprocatorsmeet the following relations:

$\mathrm{x}_{1} \mathrm{R}_{1}-\mathrm{C}_{1}>\mathrm{v}_{1} \mathrm{R}_{2}-\mathrm{C}_{2}>\mathrm{v}_{1} \mathrm{R}_{1}-\mathrm{C}_{2}>\mathrm{v}_{1} \mathrm{R}_{3}-\mathrm{C}_{3}$

This game has two pure strategy Nash equilibrium: (Cooperation, Cooperation), (Betrayal, Betrayal). Obviously, the benefits of cooperation is more than betrayal, therefore, the Nash equilibrium in this case should be (Cooperation, Cooperation).

b) If both sides respectively reciprocators and opportunists and opportunists take

betrayal while reciprocators take cooperation, the opportunist "exploit" the results of reciprocators.

Assuming the income of the betrayal opportunists is R4, and R4>R2. The successful probability for the betrayal opportunists to active alone is $\mathrm{v} 1$, the cost is $\mathrm{C} 2$. Now reciprocators who select the cooperative strategy can not only get the information or resources, but also "exploit" by the other one. Assuming the loss of reciprocators is $\mathrm{C} 4$.

Assuming reciprocators take betray a land opportunists take cooperation, the situation is as same as two reciprocators game because the opportunists are also reciprocators. Because now both sides get the same information and resources, so the successful probability for both sides to active alone is v1; 
In the same time, reciprocators who select betrayal has the first mover advantages, so their income (R2) more than the opportunists' (R3). The cost of reciprocators is C2 and the opportunists' is C3.

If both sides choose betrayal (Now the reciprocators choose betrayal because they aware the opportunists have the same intentions), the opportunists can get anything from the opportunists. Assuming the income is 0 , the loss of reciprocators is C5 (In this case the opportunists suffered fewer losses), $0 \leq \mathrm{C} 5<\mathrm{C} 4$.

Table 2 Game Matrix for one side is reciprocators and another side is opportunists

\begin{tabular}{l|l|l}
\hline \multicolumn{1}{|c|}{ opportunists } & Cooperation & Betrayal \\
reciprocators & (x1R1-C1,x1R1-C1) & $(-\mathrm{C} 4, \mathrm{v} 1 \mathrm{R} 4-\mathrm{C} 2)$ \\
\hline cooperation & (v1R2-C2,v1R3-C3) & $(-\mathrm{C} 5,0)$ \\
\hline Betrayal &
\end{tabular}

According to the different preferences of reciprocators and opportunists, suppose that the expectation income by the game between reciprocators and opportunists meet the following relations: v1R4-C2> x1R1-C1>v1R2-C2 $\geq$ v1R3-C3

This game has a pure strategy Nash equilibrium: (Betrayal, Betrayal).

Assuming opportunists active alone can get less income than cooperate with reciprocators; Assuming reciprocators suffered fewer losses than cooperate with opportunists, so they meet the following relations:

v1R4-C2 < 2(x1R1-C1), C4< x1R1-C1

a) If both sides are opportunists, when one side cooperation and the other side chose

To betray, the ones who choice cooperation are the equivalent of reciprocators. Assuming the income is R4, the successful probability of active alone is $\mathrm{v} 1$, cost $\mathrm{C} 2$. Now, the ones who Choose cooperation can not only access to information also are "exploited" by the other one. Assuming the loss is $\mathrm{C} 4$.

If both sides chose to betray, both parties are unable to get information and resources from the other side. Assuming the income is 0 .

Table 3 Game Matrix for both partners be opportunists

\begin{tabular}{l|l|l}
\hline \multicolumn{1}{|c|}{ opportunists } & Cooperation & Betrayal \\
\hline cooperation & $(\mathrm{x} 1 \mathrm{R} 1-\mathrm{C} 1, \mathrm{x} 1 \mathrm{R} 1-\mathrm{C} 1)$ & $(-\mathrm{C} 4, \mathrm{v} 1 \mathrm{R} 4-\mathrm{C} 2)$ \\
\hline Betrayal & $(\mathrm{v} 1 \mathrm{R} 4-\mathrm{C} 2,-\mathrm{C} 4)$ & $(0,0)$ \\
\hline
\end{tabular}

According to the opportunistic preference, suppose that the expectation income by the game between two opportunists meet the following relations:

$\mathrm{x} 1 \mathrm{R} 1-\mathrm{C} 1<\mathrm{v} 1 \mathrm{R} 4-\mathrm{C} 2$

The game has a pure Nash equilibrium: (betrayal, betrayal).

Based on the comparison of the above three groups of data, it is easy to get conclusion as follows:

For reciprocators, when each other are reciprocity or opportunist, Nash equilibrium of the game respectively are (cooperation, cooperation), (betrayal, betrayal); For the opportunist, when each other are reciprocity or opportunist, Nash equilibrium of the game are respectively are(betrayal, betrayal ), (betrayal, betrayal).

\section{Conclusion}

In the School - Enterprise Cooperation, if you are the reciprocator, you should looking for the same one established with reciprocal tendencies that to ensure your income. If you are opportunist, you should look for the one established with reciprocal tendencies as well, but the incomes will no more than you both are reciprocators.

Therefore, you should take the appropriate methods to maximize the benefits when you must depend on the cooperation for you development, just like Implement supervision mechanism, make 
rewards and punishments institution, To urge each other into the "reciprocity" role and so on; When you are forced to cooperate, you should pay close attention to each other to judge its tendency and adjust your own strategy in time, to minimize the loss.

\section{Acknowledgement}

This research was financially supported by the National Natural Science Foundation of China (Grant No.71303180 ) and the National Science \& Technology Pillar Program during the Twelfth Five-year Plan Period(Grant No.2013BAB07B06).

\section{References}

[1] Yuyin Yi.Evolutionary stability analysis of opportunistic behavior[J].Journal of Chongqing University (SocialEdition),2006,(1).

[2] Lebin-Xing, $\mathrm{Xu}$ Wang.The evolutionary game analysis of cooperation based onopportunistic behavior spillover[J].Journal of Industrial Engineering and Engineering Management, 2011, (3).

[3] Yuyin Yi, Tiaojun Xiao, Zhaohan Sheng.Evolutionary game analysis of opportunistic behavior in cooperative R \&D[J].Journal of Management Sciences in China, 2005, (4).

[4] Xu Wang, Zhenfeng Wang, LebinXing,Ying Dai.Evolutionary game of strategic alliance based on credit supervision and defense[J].Journal of Systems Engineering, 2008, (12).

[5] Wei Qin,FeiXu,Bo Song.Behavior of R \& D alliance partner of evolutionary game analysis -from the perspective of absorptive capacity[J].Industrial Engineering and Management, 2011, (6).

[6] JianfengLuo.The evolution of cooperation game theory of punishmentmechanism based on inter enterprise[J]. Industrial Engineering and Management, 2012, (1).

[7] XiaoliXu.Study on the motive and the formation mechanism of game from the perspective of Knowledge Alliance[D].Jiangxi University of Finance and Economics,2010. 